pre- and post-synaptic processes $(f)$ is consistent with the osmium picture in that the zone between the opposed pre- and post-synaptic membranes is wider than the zones between non-synaptic processes ${ }^{4}$ The dense band ( $d$, Fig, 1) does not appear in permanganate preparations. It appears to be extracellular material and not the middle lino of an external compound membrane ${ }^{6}$, since the line occurs when the gap between membranes is closed; in this case the gap is wider than that between opposed non-synaptic processes.

In permanganate preparations (Fig. 1, inset) the dense material associated particularly with the postsynaptic membrane does not appear: nor do the synaptic vesicles nearest the pre-synaptic membrane appear denser.

The spine seen with the light microscope in suitable preparations can thus be identified with the electron microscope. The pre-synaptic end-feet, only just visible by light microscopy ${ }^{7}$, can also readily be seen. Similar end-feet (type 1) are common on the dendrite trunks but not neuron perikarya. A full report will be published elsewhere.

I am indebted to Prof. J. Z. Young and Dr. J. D. Robertson for their interest and advice.

E. G. Gray

Department of Anatomy, University College,

London.

Feb. 24.

${ }^{1}$ Ramón y Cajal, S., Trab. Lab. Invest. Biol. Vniv. Madr., 29, 1 (1934); "Neuron Theory or Reticular Theory?" (Institito Ramón Cajal, Madrid, 1954).

2 Fox, C. A., and Barnard, J. W., J. Anat., 91, 299 (1957).

"Sholl, D. A., "The Organisation of the Cerebral Cortex" (Methuen, 1956)

4 Gray, E. G., J. Anat. (in the press).

5 Gray, E. G., J. Physiol., 145, $25 P$ (1959).

${ }^{6}$ Robertson, J. D., J. Biophys. Biochem. Cytol., 4, 349 (1958); Biochem. Soc. Symp. Biophs. Bioch 3 (1959)

'Armstrong, J., and Young, J. Z., J. Physiol., 137, 10P (1957).

\section{Identity of the Abscission-accelerating Substance in Senescent Leaves}

VAN STEVENINCK ${ }^{1}$, in a recent communication describing abscission-accelerators from lupins, has suggested a similarity of one of these substances to the abscission-accelerating factor discovered in senescent leaves ${ }^{2}$, and attributes to me the statement that the latter substance is not a sugar, amino-acid, purine or pyrimidine. In fact, in the paper in question $^{3}$ it is stated that the abscission-accelerator in senescent leaves was "so far unidentified chemically, but does not appear to be any of the more common sugars, amino-acids, purines or pyrimidines".

For clearness, it might be added that using bean explants for the bioassay, and testing a wide range of concentrations, no abscission-accelerating activity has been found for glucose, fructose, sucrose, glycine, aspartic and glutamic acids, L-valine, L-histidine, L-leucine, L-tyrosine, cysteine, methionine, adenine, guanine, xanthine, hypoxanthine or uracil.

DAPHNE J. OSBORNE

Agricultural Research Council

Unit of Experimental Agronomy,

Department of Agriculture, University of Oxford.

'Van Steveninck, R. F. M., Nature, 183, 1246 (1959).

2 Osborne, D. J., Nature, 176, 1161 (1955)

3 Osborne, D. J., Trop. Agric., 35, 145 (1958).

\section{PHYSIOLOGY}

\section{Ester Sulphate Pattern of Rabbit Bile}

Isselbacher and McCarthy ${ }^{1}$ have recently reported excretion of a sulphate conjugate of bilirubin in the bile of rats. Using paper chromatography and autoradiography of diazotized bile from rats injected with sulphate labelled with sulphur-35, they demonstrated the presence of a radioactive zone in the area of the polar azo pigment.

A series of systematic screening studies on the ester sulphate pattern of different body fluids has recently been started at our laboratory ${ }^{2,3}$. A brief account is given in the following of some observations made in this connexion on the occurrence of ester sulphates in rabbit bile.

Four adult rabbits with an average weight of $2 \cdot 5$ $\mathrm{kgm}$. were used. Doses of 5-10 mc. of radioactive sulphate were injected into the marginal vein of the ear. The rabbits (which were used for other studies as well) were kept starving in metabolic cages for $24 \mathrm{hr}$. after the injection. They were then killed by insufflation of air into the ear vein. The gall-bladders were removed, the bile emptied into test-tubes, and kept in the deep-freeze unit until used.

Of the different samples of bile obtained, 5 and 25 $\mu 1$. were subjected without any pretreatment to twodimensional paper ehromatography according to Datta, Dent and Harris ${ }^{4}$. The following solvents were used: (1) Phenol-water $(400 \mathrm{gm} .+100 \mathrm{gm}$.). A beaker containing concentrated ammonia was placed in the chromatographic tank. (2) Butanol$2 \mathrm{~N}$ ammonia (250 ml. $+250 \mathrm{ml}$.).

After drying the papers in a stream of hot air from an electric hair-drying fan, the chromatograms were subjected to autoradiography on Gevaert 'Curix' $\mathrm{X}$-ray film, exposed for one week in a wooden screwpress and developed with $G 150$.

Hydrolysing experiments with hydrochloric acid and sodium hydroxide were performed on two of the

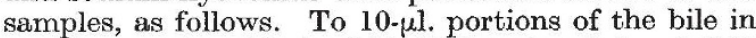
small test-tubes, $90 \mu \mathrm{l}$. of distilled water, 0.1 or $0.5 \mathrm{~N}$ hydrochloric acid or sodium hydroxide, respectively, were added. The tubes were sealed, and heated in a boiling water-bath for 15,30 or $60 \mathrm{~min}$. After cooling, the tubes were opened and the solutions evaporated to dryness in an exsiccator. The residues were dissolved in $10 \mu \mathrm{l}$. of water, and $5-\mu \mathrm{l}$. portions of these solutions were subjected to combined chromato-autoradiography as previously described.

A typical result of this study is presented in Fig. 1. All biles so far investigated showed the same type of pattern of radioactive spots on the autoradiograms. In addition to the occurrence of some radioactivity at the starting point of the chromatogram (1), corresponding to labelled material which did not move in either of the solvents used, and the distinct spot of inorganic sulphate (2), at least six other compounds labelled with sulphur-35 were visualized (201-206). Most of these spots were fairly resistant to alkaline hydrolysis $(0.5 \mathrm{~N}$ sodium hydroxide for $60 \mathrm{~min}$. at $100^{\circ} \mathrm{C}$.), since only minor changes in the pattern occurred under these conditions.

Heating in hydrochloric acid, on the other hand, destroyed the whole pattern. Thus, after heating in $0.5 \mathrm{~N}$ hydrochloric acid for $15 \mathrm{~min}$. at $100^{\circ} \mathrm{C}$., all the 201-206 spots vanished, and a marked increase in the inorganic sulphate spot took place.

Although none of the 201-206 spots has as yet been identified, it appears that a fairly large number 